
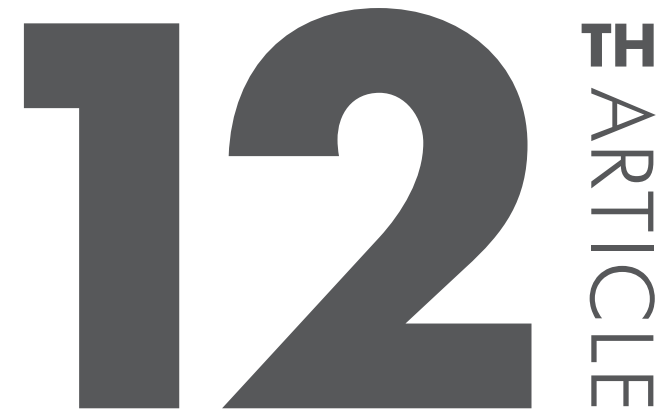

\title{
Electrocatalytic reduction of hydrogen peroxide performed by poly(pyrrole) / Prussian blue composites
}

Rafael N. Soek, Ariane Schmidt, Leandro Hostert and Marcio Vidotti*

Grupo de Pesquisa em Macromoléculas e Interfaces - Universidade Federal do Paraná, Dep. Química, C.P. 19081, 81531-980 Curitiba, Paraná, Brazil

*mvidotti@ufpr.br

\section{ABSTRACT}

The present work describes the electrochemical and electrocatalytic effect showed by poly(pyrrole) / Prussian blue composites. The material was synthesized onto platinum surface in a rapid and straightforward methodology based on the electrodeposition of poly(pyrrole) in a presence of $\mathrm{Fe}(\mathrm{CN})_{6}^{3-}$ ions. The modified electrode showed the electrocatalytical reduction of $\mathrm{H}_{2} \mathrm{O}_{2}$ and a remarkable durability if compared with pure $\mathrm{PB}$ electrodes showing that the presence of the conducting polymer leads to an increment of the inorganic stability.

Keywords: Polypyrrole; Prussian Blue; Immobilization, Conduction polymer 


\section{INTRODUCTION}

The increasing interest on conducting polymers can be associated to its unique physical chemical properties, a special one is centered on the immobilization of different species, such as inorganic nanomaterials and biocompounds. The main interest in this kind of assembly is the enhancement of electron transfer reactions, which is a fundamental characteristic needed for the fabrication of high efficient electrochemical sensors based on electrocatalytic reactions. One of the most studied inorganic electrocatalytic material is the Prussian Blue (PB), which performs the reduction of hydrogen peroxide at low potentials and can act together with poly(pyrrole) which is amongst the conductive polymers, one of the most stable in a different range of $\mathrm{pH}$. Hydrogen peroxide is an important chemical to study in various fields, such food, medicine, clinical, industrial and environmental analysis [1]. In biosensor science, the $\mathrm{H}_{2} \mathrm{O}_{2}$ is the product of many different enzymatic reactions. The most known is the Glucose oxidase reaction, vastly employed in commercial biosensors [2].

Conducting polymers contain a unique conjugation consisting on alternate double and single bonds along the main chain. This extended $\varpi$-conjugated system leads to its intrinsic properties, such as high electrical conductivity, low energy optical transitions, low ionization potential and high electron affinity [3]. All these interesting features allow the use of conducting polymers in different fields of technology such as solar cells, light weight batteries, electrochromic devices, sensors, molecular electronic devices supercapacitors for energy storage and secondary batteries [2-4].

Amongst the conducting polymers poly(pyrrole) has special role due to its easy preparation and good stability over a wide range of $\mathrm{pH}$. The polymerization can be divided into three major classes: (I) chemical [5-7], (II) photo induced [8] and (III) electrochemical methods $[9,10]$, where each group has its advantages depending on the utilization aimed. However, when the focus is the superficial modification of electrodes, by far the electrochemical method provides easy control of key parameters such as thickness and morphology [11] besides problems regarding the film adherence can be surpassed [12]. In Figure 1 is shown the structure of poly(pyrrole).

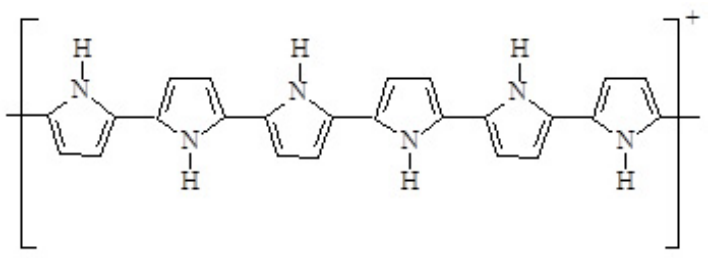

Figure 1. Structure of poly(pyrrole). 
Prussian Blue (PB) or ferric hexacyanoferrate, is the one of the most studied coordination compound reported in the scientific literature. $\mathrm{PB}$ is commonly synthesized by mixing ferric (III) with hexacyanoferrate (II). Equations 1 and 2 show the electrochemical method of synthesis of PB. In this process, hexacyanoferrate (III) is electrochemically reduced to hexacyanoferrate (II) that rapidly react with the ferric (III) ions to form the PB [13].

$$
\begin{aligned}
& {\left[\mathrm{Fe}^{\mathrm{III}}(\mathrm{CN})_{6}\right]^{3-}(\mathrm{aq})+\mathrm{e}^{-} \rightarrow\left[\mathrm{Fe}^{\mathrm{II}}(\mathrm{CN})_{6}\right]^{4-}(\mathrm{aq})} \\
& 3\left[\mathrm{Fe}^{\mathrm{II}}(\mathrm{CN})_{6}\right]^{4-}(\mathrm{aq})+4 \mathrm{Fe}^{3+}(\mathrm{aq}) \rightarrow \mathrm{Fe}_{4}^{\mathrm{III}}\left[\mathrm{Fe}^{\mathrm{III}}(\mathrm{CN})_{6}\right]_{3}(\mathrm{~s})
\end{aligned}
$$

As commented previously, PB has been used for the construction of electrocatalytic sensors towards the reduction of hydrogen peroxide [14-15]. Nevertheless, the PB stability onto electrodes is relatively low and many different factors such as low adhesion, loss of electric contact, electrochemical irreversibility and $\mathrm{pH}$ changes can act together leading to a diminishment of the electrode utilization. An improvement on the PB stability can be achieved with the incorporation of poly(pyrrole) acting as host of $\mathrm{PB}$ particles, with this methodology it is intended that the strong interaction between PPy and PB lead to an unique composite material with remarkable electronic transfer and high stability.

\section{RESULTS AND DISCUSSION}

\subsection{Electrochemical Polymerization of PPy and formation of PB-PPy}

The poly(pyrrole) films were synthesized at potentiostatic conditions by applying $1.0 \mathrm{~V}$ (vs $\mathrm{Ag} / \mathrm{AgCl}$ ) until the charge passed through the electrode reached $5 \mathrm{mC}$. This is a simply methodology used in order to get the very same amount of PPy in all measurements. It is well known in literature that the polymerization of PPy is followed by the insertion of anionic species through the material in order to balance the positively charged polymer [16]. By this way, the PPy layer was formed in the presence of $\left[\mathrm{Fe}(\mathrm{CN})_{6}\right]^{3-}$ which is incorporated in the polymeric matrix, acting as a seed for the growth of $\mathrm{PB}$ particles, when in the presence of cations $\mathrm{Fe}^{3+}$ within the PPy film. These steps are schematically shown in Figure 2. 


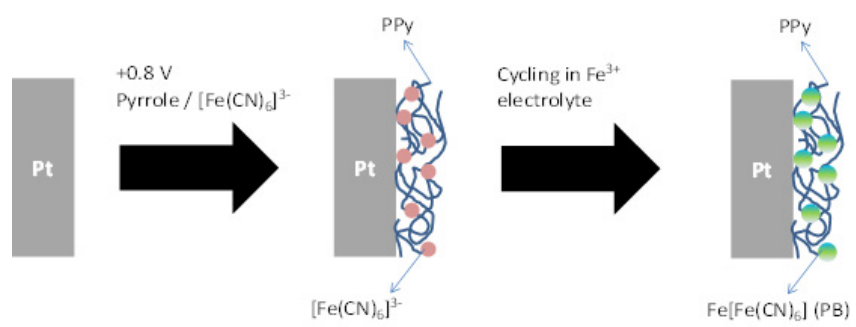

Figure 2. Scheme of the main steps employed for the synthesis of PPy/PB composite modified electrodes.

In Figure 3 are shown the cyclic voltammograms performed for different modified electrodes. In blue line is shown the voltammetric behavior of a platinum electrode modified by pure Prussian blue synthesized by electrochemical deposition, it is possible to observe the reversible redox behavior at $0.23 / 0.18 \mathrm{~V}$. The red line corresponds to the PPy film in the presence of incorporated hexacyanoferrate ions which can be evidenced by the large voltammetric waves centered in $0.28 / 0.18 \mathrm{~V}$, this mean that the $\mathrm{PPy} /\left[\mathrm{Fe}(\mathrm{CN})_{6}\right]^{3-}$ ions are strongly adsorbed on the PPy chain. Within this potential window it is not possible to observe the redox peaks of PPY which are located at approximately $-0.8 \mathrm{~V} \mathrm{[17],} \mathrm{so} \mathrm{by} \mathrm{this} \mathrm{way,} \mathrm{the}$ PPy is in its oxidized form which represents the most conductive state of the polymer, nevertheless, the presence of PPy is easily observed by the capacitive behavior of the voltammogram. Finally, in black line is shown the PPy/PB composite, after cycling in $\mathrm{Fe}^{3+}$ electrolyte. At first view, the behavior is quite similar from $\mathrm{PPy} /$ $\left[\mathrm{Fe}(\mathrm{CN})_{6}\right]^{3-}$ modified electrode apart from the narrowing of the oxidation wave and the appearing of a discrete reduction peak at $0.19 \mathrm{~V}$ which is a clear evidence of the PB formation. It is important to note that this electrode was submitted to over 100 cycles without the loss of electroactivity, indicating that the PPy in fact stabilizes the PB particles. As commented previously, the PPy is in its oxidized form which probably strong interacts with negatively charged $\mathrm{PB}$ particles producing high stable composite. 


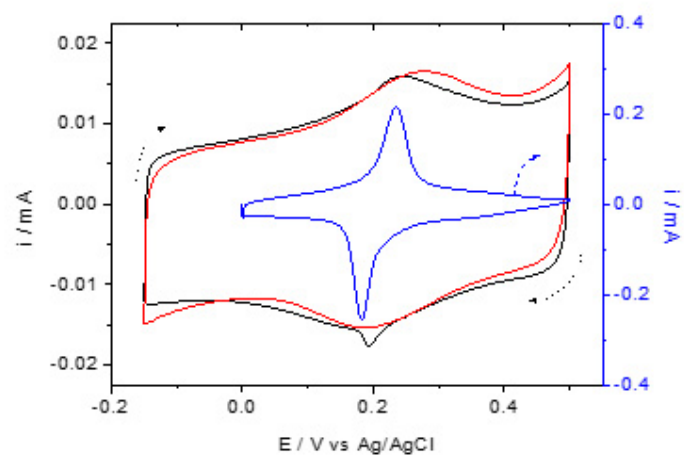

Figure 3. Cyclic voltammograms performed in $\mathrm{KCl} 0.1 \mathrm{~mol} \mathrm{~L}^{-1} \mathrm{pH} 3$, scan rate of $25 \mathrm{mVs}^{-1}$ of electrodes modified by (-) $\mathrm{PB}$, $(-) \mathrm{PPy} /\left[\mathrm{Fe}(\mathrm{CN})_{6}\right]^{3-}$ and (-) PPy/PB.

\subsection{Electrocatalysis of $\mathbf{H 2 O 2}$}

The hydrogen peroxide is the product of many enzymatic reactions and also the raw material in several industrial processes [18], therefore the accurate and selective determination of hydrogen peroxide draws the attention of many scientists and engineers because of its numerous practical applications. The electrocatalysis performed by PB electrodes is shown in Figure 4. In the scheme the overall electrocatalytic reaction is depicted. The hydrogen peroxide is reduced to water by the PB (in the reduced form) which is immediately oxidized to PB (OXI). This reaction is evidenced in the cyclic voltammogram with the increase of the cathodic current under the potential of $0.19 \mathrm{~V}$ corroborating that only the reduced form of $\mathrm{PB}$ reacts with $\mathrm{H}_{2} \mathrm{O}_{2}$. As expected the anodic current drops down as a consequence of the reaction turnover and with the increase of $\mathrm{H}_{2} \mathrm{O}_{2}$ concentration $(0$ up to $\left.50 \mathrm{mmol} \mathrm{L}^{-1}\right)$.

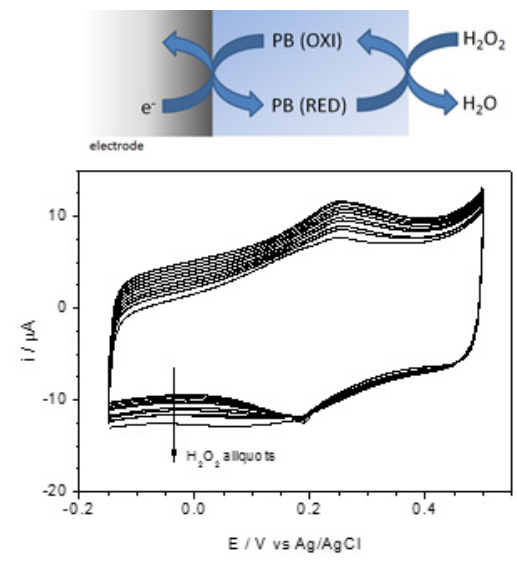

Figure 4. Scheme of the electrocatalytic behavior of PPy/PB modified electrode. Cyclic voltammograms performed by modified electrodes in $\mathrm{KCl} 0.1 \mathrm{~mol} \mathrm{~L}^{-1} \mathrm{pH} 3$ containing different amounts of $\mathrm{H}_{2} \mathrm{O}_{2^{\prime}}$ scan rate of $25 \mathrm{mV} \mathrm{s}^{-1}$. 
One important point raised by these results is the possibility of assembly enzymes on the modified electrode surface. The presence of PPy allows the incorporation of biomolecules, such as enzymes towards the development of biosensors [19]. The high stability found for this composite and the electrocatalytic behavior found even for a small amount of incorporated PB is a very interesting behavior that indicates a promising tool for the development of electrochemical sensors for the detection of $\mathrm{H}_{2} \mathrm{O}_{2}$ in different media and environmental conditions.

\section{CONCLUSIONS}

A composite material formed by poly(pyrrole) and Prussian blue was successfully reported. The synthesis followed a rapid and straightforward methodology employing aqueous solutions with very small amount of reactants. The composite material showed high electroactivity and stability as studied by cyclic voltammograms and also presented a very interesting electrocatalytic behavior towards the reduction of hydrogen peroxide which is an important specie to be detected in either industrial and medicinal fields.

\section{FUTURE PERSPECTIVES}

As can be seen on this work the composite material showed very interesting characteristics for the development of electrochemical sensors. Enhanced sensitivities might be found by incorporating more amounts of PB in the PPy polymeric matrix. By this way intense efforts are being made in order to achieve this goal.

\section{ACKNOWLEDGMENTS}

The authors would like to thank Brazilian supporting agencies CAPES and CNPq for funding and scholarship grants.

\section{REFERENCES}

[1] F. Doroftei, T. Pinteala, A. Arvinte, Microchim. Acta., 181 (2013) 111.

[2] J. Wang, Chem. Rev., 108 (2008) 814.

[3] A.K. Wanekaya, Y. Lei, E. Bekyarova, W. Chen, R. Haddon, A. Mulchandani, N.V. Myung, Electroanalysis., 18 (2006) 1047.

[4] M. Gerard; A Chaubey; B.D. Malhotra, Biosens. Bioelectron., 17 (2002) 345.

[5] A. Angeli, Gazz, Chim. Ital, 46 (1916) 279.

[6] E.J. Oh, K.S. Jang, A.G. MacDiarmid, Synth. Met., 125 (2002) 297.

[7] M.C. Henry, C.C. Hsueh, B.P. Timko, M.S. Freunda, J. Electrochem. Soc., 
148 (2001) 155.

[8] Q. Fang, D.G. Chetwynd, J.W. Gardner, Sens. Actuators A, 99 (2002) 74.

[9] E.M. Genies, G. Bidan, A.F. Diaz, J. Electroanal. Chem., 149 (1983) 101

[10] W. Schuhmann, R. Lammert, B. Uhe, H.L. Schmidt, Sens. Actuators B, 1 (1990) 537.

[11] H.L. Schmidt, F. Gutberlet, W. Schuhmann, Sens. Actuators B, 13 (1993) 366.

[12] A. Ramanavicius, A. Ramanaviciene, A. Malinauskas, Electrochimica Acta, 51 (2006) 6025.

[13] A.A. Karyakin, Electroanalysis., 13 (2001) 813.

[14] J. Zeng, W. Wei, X. Liu, Y. Wang, G. Luo, Microchim. Acta., 160 (2008) 261.

[15] J. Tao, G. Xu, H. Hao, F. Yang, K. Ahn, W. Lee, J. Electroanal. Chem., 689 (2013) 96.

[16] L. H. Dall'Antonia, M. Vidotti, R. M. Torresi, S. I. Córdoba de Torresi. Electroanalysis, 14 (2002) 1577.

[17] M. Wysocka-Żołopa, E. Gr dzka, K. Szyma ski, K. Winkler, Thin Solid Films, 548 (2013) 548, 44.

[18] N.A. Sitnikova, A.V. Borisova, M.A. Komkova, A.A. Karyakin, Anal. Chem., 83 (2011) 2363.

[19] J.-C. Vidal, J. Espuelas, E. Garcia-Ruiz, J. -R. Castillo, Talanta, 64 (2004) 655. 
116 